\title{
An Example of a Study with Instructed Music Listening Activities with Information and Concert Event Content
}

\author{
Ajda Şenol Sakin ${ }^{1} \&$ Gülnihal Gül ${ }^{1}$ \\ ${ }^{1}$ Music Education Department, Bursa Uludag University, Bursa, Turkey \\ Correspondence: Ajda Şenol Sakin, Music Education Department, Bursa Uludag University, Bursa, Turkey. \\ E-mail: ajdasenol@gmail.com
}

Received: March 9, 2021

doi:10.5539/ies.v14n8p14
Accepted: April 14, $2021 \quad$ Online Published: July 22, 2021

URL: https://doi.org/10.5539/ies.v14n8p14

\begin{abstract}
It is thought that music education in general education, especially for individuals of all ages and levels, is important in the musical development of the individual. Besides, it is seen that the "listening-singing" learning area in general music education teaching programs has an important weight in the program. In this context, it is considered necessary that music listening activities carried out for this learning area should be among the main activities that support other musical activities in classroom music education, which form the basis for the students to benefit from music education. For this reason, it is thought that the active participation of the students in music listening activities will contribute to effective and efficient music education. With this study, it is aimed to determine the contribution of instructed music listening activities to music culture learning outcomes in secondary school music education. For this purpose, an instructed music listening activity was held for students in a secondary school. The effect of the activity performed on the level of success was measured with knowledge tests. According to the results it is found that most of the students achieved an above-moderate success from the recorder family knowledge test.
\end{abstract}

Keywords: music listening activities, recorder family, music history periods, music education, secondary school

\section{Introduction}

Within the scope of music education, it is expected that the individual will gain musical personality, develop his aesthetic aspect and creative power, listen to, understand and explain music, acquire knowledge about music culture, and transfer this knowledge to his social life. It is thought that music education in general education, especially for individuals of all ages and levels, has an important contribution to this expected musical development. In this context, there are four learning areas secondary music lesson education programs, namely "listening-singing, musical perception and information, musical creativity and music culture" (Ministry of National Education, 2018). One of the aims of the programs within the scope of these learning areas is to "engage the student in the listening and singing activities individually and collectively". It was determined that the recommended time for listening-singing learning area in music lesson time varied between $47 \%$ and $50 \%$ according to grade level. From this point of view, the importance of listening-singing is seen in the realization of an effective learning-teaching process within the scope of general music education.

In this context, music listening activities are considered as one of the main activities that support other musical activities in-classroom music education and that form the basis for the student to benefit from music education (Özkeleş \& Nayır, 2015; Özen, 2016). For this reason, it is important to ensure the active participation of the student in music listening activities. This will only be possible if they learn how to listen to music.

It is stated that music listening strategies are important in addition to attention in music activities. Music listening strategies which are classified as cognitive, relational, objective analytical and emotional, differ between those who interpret what they hear through emotional or non-musical relationships with music, and those who interpret them with theme and form and such musical analysis (Hargreaves \& Colman, 1981; Anderson, 2015). For this reason, it is very important for the student to learn to listen to music.

Listening to music, which is a latent behaviour, is a very special activity that cannot be determined how the individual is emotionally and intellectually affected and cannot be observed by others. And full communication in this special activity can be achieved through the active participation of the audience in the musical communication 
process (Kratus, 2017; Reitan, 2013). Listening types can be considered as active and passive. In passive listening, the music $\mathrm{s} /$ he listens to is not important for the individual. In active listening, the audience perceives and listens to elements of the piece (harmonic structure, sounds, lyrics, etc.) (Şenoğlu Özdemir \& Can, 2019). Thus, it is necessary for the student to focus on the music s/he listens during the music listening activity and be an active listener to contribute to the musical development process. The student's gaining active listening skill is directly proportional to the effective and efficient teaching process (Cusano, 2004). In this context, guiding the student by speaking during the listening process in general music education will contribute positively to her/his participation in the active listening process (Georgii-Hemming \& Kvarnhall, 2015). The teacher can guide the student by explaining different elements of the pieces (instruments, differences, and features of the instruments, the musical structure of the piece, etc.).

Within the scope of the field of learning music culture in general music education, students are expected to develop music culture, recognize and distinguish music types in Turkey and in the world. For this purpose, music history periods are included in music lesson, different types of music, composers, period features and sample works are included in the music lesson curriculum in this context. Thus, while contributing to the music culture of the student, support is also provided for their musical perception and knowledge.

However, it is thought that only the theoretical explanation about the music history subjects will not support effective and permanent learning. For this reason, it is considered necessary to carry out the visual and audio supported course activities. It is stated in various studies that visual and auditory supported activities contribute positively to the learning process of the student (Aslan Efe \& Bakır, 2019; Aytan, Güneş, \& Uysal, 2018; Baldridge, 1894; Güzel, Çakır, \& Çelen, 2020; Martinez, 2015, Mobbs \& Cuyul, 2018; Simm \& Nolker, 2002).

For this reason, it is thought that giving visual and auditory supported activities in music lessons will contribute to achieving the targeted achievements, and also instructed music listening activities supported by visuals will accelerate this process. These thoughts are supported by studies. Studies in the literature suggest that the lessons that include instructed music listening activities support the learning process (Campbell, 2005; Georgii-Hemming \& Kvarnhall, 2015; Woody, 2004; Şenoğlu Özdemir \& Can, 2019).

Recorder is frequently used to instrument training of general music education in Turkey. The fact that it is an educational instrument, its ease, being a real art instrument and having a family with different sound colors makes the recorder interesting. The recorder family, which was common in the Renaissance period and was included in orchestras in the Baroque period, named after the different vocal ranges. Members of the flute family are piccolo or sopranissimo recorder, soprano or descant recorder, alto or treble recorder, tenor recorder, bass or basset recorder, (great) bass or quart-bass recorder, contrabass or great bass or sub-bass recorder, sub-great bass or contra-great bass or contrabass and sub-contrabass or double contrabass (octocontrabass) recorder. But usually used soprano, alto, tenor and bass recorder.

In this study, the research question was determined as; "What are the contribution of instructed music listening activities in teaching recorder flute family and music history periods?". In line with the question, answers to the following sub-problems were sought:

1) What is the students' recognition status of recorder family?

2) What is the students' recognition status of music history periods in terms of general features, composers, instruments and musical composition?

With this in mind, the study aimed to determine the contribution of instructed music listening activities to music culture learning outcomes in secondary school music education. For this purpose, instructed music listening activity was held with recorder family for music history periods. In Turkey, the recorder is widely used as music education instruments and has a large family in terms of sound, structure and technical features.

\section{Method}

In the research, one-shot case study design model was used. In such research, experimental groups are taken as they are naturally shaped. In this model, the data is based only on the post-test (Kaptan, 1995; Karasar, 2008).

In the study, randomly were chosen from the 7th and 8th-grade students of secondary education, and an instructed music listening activity was conducted with the recorder family. The effect of the activity performed on the level of success was measured with success tests prepared for the topics covered in the activity.

\subsection{Study Group}

The population of the study is composed of primary schools affiliated to the Ministry of National Education, while the sample is composed of the 7th and 8th-grade students in the 2019-2020 academic year in a secondary school in 
Bursa. Of the 81 students participating in the research, 32 are 7 th-grade students and 49 are 8 th-grade students. The reason for choosing 7 th and 8 th-grade students for the study is that the subject and music history periods included in the instructed music listening activity are included in the 5th and 6th-grade music lesson acquisitions and that the students are thought to be partially equipped about these topics.

\subsection{Application Process}

For the activity organized to introduce primary school students through the instructed music listening activity of the music history periods and recorder family, which has been used in general music education for many years, firstly materials were developed by a group of students from Bursa Uludag University Faculty of Education, Department of Fine Arts Education, Department of Music Education, who took the course of Instructional Technologies and Material Development in the 2018-2019 academic year, and the pieces to be performed at the concert were studied with recorder family.

The first aim of the developed materials was to write a story that introduces the recorders in the recorder family, appropriate to the level of the students to attract their attention. In the written story, sopranino, soprano (descant), alto (treble), tenor and bass recorders were revived as family members; the loudness of the instruments, the keys they use and the lowest notes that can be played are mentioned. The story was visualized by using the PowerPoint program. A similar way was followed to explain the periods of music history through instructed music listening activity and presentations with important composers, instruments, musical compositions, and major features of the period were prepared to be used before the performed pieces.

In the instructed music concert event, the following pieces were performed to exemplify the periods of music history with the recorder family:

(1) "Greensleeves" was a British Folk Song of the Renaissance period and it was transcribed for recorder family by A. Isozaki.

(2) "Autumn" was the Baroque period piece and it was transcribed for recorder family by David Burndrett from the A. Vivaldi's Four Seasons Violin Concertos.

(3) W. A. Mozart's piece "Motet, Ave Verum Corpus" from the Classical Period.

(4) "Trout Quintet" was a Romantic Period piece and it was transcribed for recorder family by David Burndrett from the F. Schubert's The Trout Quintet.

(5) Turkish folk song “Çanakkale Türküsü” was transcribed for recorder family by Uğur Çetintaş.

Of these pieces, Greensleeves is arranged for 2 sopranos, alto and tenor recorders, Autumn and Motet, Ave Verum Corpus are arranged for soprano, alto, tenor, bass recorders, and piano, Trout Quintet, and Çanakkale Türküsü are arranged for soprano, alto, tenor, and bass recorders.

The event took place in the primary school's concert hall. First, a story presentation and instructed music listening activity were performed. Then, worksheets on the subject of the recorder family were given to the students and then a knowledge test was applied to this topic. Finally, a similar application was carried out regarding the music history periods.

\subsection{Data Collection}

In the research, worksheets were prepared for students in order to consolidate the topics described in instructed music listening activity. And knowledge tests were prepared for the determination of knowledge levels. The worksheets and knowledge tests were created by the researchers. Particular attention was paid to the fact that worksheets and knowledge tests included questions of different difficulties and types. The created worksheets and knowledge tests took their final form by consulting 3 music teachers teaching at the 7 th and 8 th-grades.

Worksheets and knowledge tests content and preparation processes are given below as a list:

Recorder family worksheet: The worksheet contains the following sections;

(1) puzzle where the names of the instruments should be placed,

(2) the story about the names of the instruments in the recorder family, their loudness, the key they use, the lowest notes that can be played on these instruments, and true/false questions prepared for this story,

(3) matching questions: instrument pictures, names, and loudness,

(4) matching questions: instrument pictures and the key they use.

The knowledge test for the recorder family: The knowledge test, prepared for this subject consists of 15 questions. With these questions, it was tried to determine to what extent the students knew the topics explained in the 
instructed music listening activity directed to the family of the recorder.

Music history periods worksheet: The worksheet consists of the following sections;

(1) puzzle where the names of the different musical compositions should be placed (for example motet, opera, symphony, etc.),

(2) word hunt to find different musical instrument names,

(3) brief information about the periods (composers, instruments, musical compositions, and period features),

(4) matching questions: composers, periods and musical compositions,

(5) true/false questions.

The knowledge test for period of music history: This knowledge test consists of 5 parts and 34 questions.

(1) true/false questions,

(2) gap-filling questions,

(3) matching questions: musical compositions and their definitions,

(4) multiple-choice questions

(5) matching questions: composers, periods, and instruments.

\subsection{Analyzing of Data}

In the research, the knowledge tests prepared for data collection were scored separately, and the knowledge levels of students' after the instructed music listening activity were measured. In both knowledge tests, the success level is grouped according to the five-point chart, and the success levels are obtained by dividing the number of questions.

The success status of students for the recorder family knowledge test, which includes fifteen questions, was determined according to the number of questions they answered correctly. Accordingly, the success assessment scale was determined as superior success (13-15 questions), successful (10 - 12 questions), moderate (7 - 9 questions), weak (4 - 6 questions), unsuccessful (0 - 3 questions).

A similar application was applied for the knowledge test of music history periods. The assessment scale for the knowledge test was determined as superior success (29 - 34 questions), successful (22 - 28 questions), moderate (15 - 21 questions), weak (8 - 14 questions), unsuccessful (0 - 7 questions).

The success levels determined according to the number of questions answered by the students were resolved with frequency and percentage method.

\section{Results}

In this section, the knowledge levels of the students who participated in the research after the instructed music listening activity are included.

Table 1 shows the success levels of the students participating in the research from the knowledge test for the recorder family after the instructed music listening activity.

Table 1. Recorder family knowledge test success status

\begin{tabular}{lcccccc}
\hline & \multicolumn{2}{c}{ 7th Grade } & & 8th Grade & \multicolumn{2}{c}{ Total } \\
\hline & $\mathrm{n}$ & $\%$ & $\mathrm{n}$ & $\%$ & $\mathrm{n}$ & $\%$ \\
\hline Superior Success & 9 & 28.12 & 17 & 34.70 & 26 & 32.1 \\
Successful & 11 & 34.38 & 19 & 38.77 & 30 & 37.03 \\
Moderate & 11 & 34.38 & 10 & 20.40 & 21 & 25.93 \\
Weak & - & - & 3 & 6.13 & 3 & 3.7 \\
Unsuccessful & 1 & 3.12 & - & - & 1 & 1.24 \\
Total & 32 & 100 & 49 & 100 & 81 & 100 \\
\hline
\end{tabular}

When Table 1 is examined, from the recorder family knowledge test applied after the instructed music listening activity $37.03 \%$ of the students are successful, $32.1 \%$ are superior, $25.93 \%$ are moderate, $3.7 \%$ are weak and $1.24 \%$ are unsuccessful.

Prepared as multiple-choice questions, the question "Which of the following recorder's lowest note is fa?" is the 
most difficult question for students in the recorder family knowledge test. It was determined that only $38.27 \%$ of the students answered the question correctly. Also, it was determined that they had difficulty in questions matching the keys they used with the recorder family pictures and only 35 students $(43.21 \%)$ answered this section completely.

The findings of the students' answers to the recorder family knowledge test are as follows:

- From the true/false questions, "sopranino recorder's lowest note is F" (46 students, 56.79\%).

- Sorting recorder family members from smallest to biggest according to the sound color (47 students, $58.02 \%)$.

- From multiple choice questions, "Which member of the recorder family has a medium-pitched sound color?" (52 students, $64.19 \%$ ).

- "The name of the recorder family member used in music lessons" question (52 students, $64.19 \%$ ).

- From the true/false questions, "bass recorder tunes are written with the key F" (59 students, $72.83 \%$ ).

- $\quad$ From the multiple choice questions, "Which recorder whose sound color is lower than tenor recorder?" (63 students, $77.77 \%$ ).

- From the true/false questions, "the alto recorder sound range is lower than the bass recorder" (67 students, $82.71 \%)$.

- In the open-ended question asking for the name of the biggest member of the recorder family (70 students, $86.41 \%)$.

- In the open-ended question asking the name of the instrument family (73 students, $90.12 \%$ ).

The success status of the students participating in the research from the knowledge test of music history periods after the instructed music listening activity is given in Table 2.

Table 2. Music history periods knowledge test success status

\begin{tabular}{lcccccc}
\hline & \multicolumn{2}{c}{ 7th Grade } & \multicolumn{2}{c}{ 8th Grade } & \multicolumn{2}{c}{ Total } \\
\hline & $\mathrm{n}$ & $\%$ & $\mathrm{n}$ & $\%$ & $\mathrm{n}$ & $\%$ \\
\hline Superior Success & - & - & - & - & - & - \\
Successful & - & - & 5 & 10.20 & 5 & 6.17 \\
Moderate & 7 & 21.87 & 20 & 40.82 & 27 & 33.33 \\
Weak & 21 & 65.63 & 21 & 42.85 & 42 & 51.85 \\
Unsuccessful & 4 & 12.5 & 3 & 6.13 & 7 & 8.65 \\
Total & 32 & 100 & 49 & 100 & 81 & 100 \\
\hline
\end{tabular}

According to table 2, it is seen from the knowledge test of music history periods that $33.33 \%$ of the students showed a moderate success, $51.85 \%$ were weak, $8.65 \%$ unsuccessful, and $6.17 \%$ successful. There are no students who showed superior success at the music history periods knowledge test.

In addition, the number of questions that students answered correctly in terms of different sections from the knowledge test of music history periods is shown in Table 3.

Table 3. Music history periods' knowledge test success status by question types

\begin{tabular}{|c|c|c|c|c|c|c|c|c|c|c|c|c|c|c|c|}
\hline \multirow{3}{*}{\multicolumn{2}{|c|}{ Question Type }} & & \multicolumn{12}{|c|}{ Number of Correctly Answered Questions } & \multirow{3}{*}{ Total } \\
\hline & & & \multicolumn{2}{|r|}{5} & \multicolumn{2}{|r|}{4} & \multicolumn{2}{|r|}{3} & \multicolumn{2}{|r|}{2} & \multicolumn{2}{|c|}{1} & \multicolumn{2}{|c|}{0} & \\
\hline & & & $\mathrm{n}$ & $\%$ & $\mathrm{n}$ & $\%$ & $\mathrm{n}$ & $\%$ & $\mathrm{n}$ & $\%$ & $\mathrm{n}$ & $\%$ & $\mathrm{n}$ & $\%$ & \\
\hline True/False Questions & & & 5 & 6.17 & 9 & 11.11 & 58 & 71.62 & 5 & 6.17 & 4 & 4.93 & - & - & 81 \\
\hline Gap-filling Questions & & & 6 & 7.40 & 10 & 12.34 & 21 & 25.92 & 21 & 25.92 & 11 & 13.58 & 12 & 14.84 & 81 \\
\hline $\begin{array}{l}\text { Matching questions } \\
\text { composition }\end{array}$ & about & musical & - & - & - & - & 8 & 9.87 & 13 & 16.04 & 27 & 33.33 & 33 & 40.76 & 81 \\
\hline Multiple choice questions & & & 1 & 1.23 & 14 & 17.28 & 28 & 34.56 & 22 & 27.16 & 14 & 17.28 & 2 & 2.49 & 81 \\
\hline
\end{tabular}

When Table 3 is analysed, it was determined that most of the students (58 students, $71.62 \%$ ) answered the 3 
true/false questions correctly about composer, instrument, and musical compositions. Also, there were no students who answered the whole section incorrectly.

When the responses given to the gap-filling questions containing composers, instruments, and period features are examined; it is seen that 21 students $(25.92 \%)$ answered 3 questions correctly, and 21 students $(25.92 \%)$ answered 2 questions correctly. It is also seen that there are students answer all questions correctly (6 students, 7.40\%), and also there are students who do not answer all questions or answer all questions incorrectly.

In matching questions of musical compositions and their definitions, $40.76 \%$ (33 students) of the students either did not answer the questions at all or answered all of them incorrectly.

According to Table 3, about the multiple questions, it is seen that $34.56 \%$ (28 students) of the students answered 3 questions correctly, 1 student (1.23\%) answered all questions correctly and 2 students (2.49\%) answered all questions incorrectly.

In addition, students were generally challenged in the matching questions about composer, periods and musical compositions. There is only 1 student $(1.23 \%)$ who answered all these questions correctly.

\section{Discussion}

According to the results of the instructed music listening activity with the recorder family, it is seen that most of the students achieved an above-moderate success from the recorder family knowledge test. The reason can be considered why the success is above-moderate with the superior success students $(32.1 \%)$ is that the instructed music listening activity is realized with the recorder family thus this activity enabled students to use their audio-visual memory. In the literature, there are studies showing that the activities performed with visual and audio materials have an effect on increasing student achievement. These studies also support studies that were conducted. Erden (2012) determined that computer-aided visual teaching materials are effective in increasing success and shortening the duration of education in technology education lessons. In their study, Gülen and Demirkuş (2014) showed that visual materials in science education increased student success; and in the study conducted by Çelik (2010), the applications based on video recording in piano education provided some increase in students' self-assessment skills; Arslan (2008) concluded that the use of audio-visual materials had a positive effect on the learning process in primary school Revolution History and Kemalism lesson. Based on this, it is thought that more permanent and effective results can be obtained with education supported by visual and audio materials. With this in mind, it is considered important to include music education activities supported by visual and audio materials in the music education process.

In the knowledge test of music history periods, students' success levels were found low. When the success levels were examined, it was determined that more than half of the students showed below-moderate success $(51.85 \%$ weak, $8.65 \%$ unsuccessful). As a result of the examinations, it is seen that the students have difficulties mostly in musical compositions, and definition matching and composer, period, and instrument matching sections. This situation is thought to arise from the explanation of four different musical history periods (Renaissance, Baroque, Classical, Romantic) in terms of the composer, instrument, musical compositions, and musical history features within a single event. Besides, considering the student attention periods, the activity period of the students was long thus student success is thought to be negatively affected by these reasons.

Nevertheless, the students who participated in this kind of activity for the first time focused on the instruments and music they saw more than the subject content and that affected their success. Besides, it is thought that applying the worksheets and knowledge tests prepared for the recorder family without interruption at the end of the instructed music listening activity, and worksheet and knowledge tests for the music history periods immediately afterward also affected the success.

It was observed that performing the study in the concert hall, and the long duration of the activity and the measurement process negatively affect the attention of the students. Although students' success levels in music history periods test are not very high, they have taken a big step towards getting to know music history periods in terms of the composer, musical compositions, instruments, and general features; Also they had the opportunity to listen to the live recorder family concert.

In addition, verbal opinions were received from school music teachers and students who participated in the study that they found the instructed music listening activity was impressive and informative. Similarly, there are studies in the literature expressing that instructed music listening activities contribute positively to the learning process of the students.

In his research, Anderson (2015) performed listening activities designed according to the instructions of the students in the experimental group, while the control group students listen to music without interfering. As a result 
of the study, it was concluded that there was a significant difference in the music listening sensitivity and music listening pleasure scores of the experimental group students who joined instructed music listening activities.

Todd and Mishra (2013) stated that guided listening activities increase students' participation and attention in their study. These studies are similar to the results obtained in line with the findings obtained from the research. From this point of view, it is thought that having instructed music listening activities in music education will increase the students' attention and contribute to their musical sensitivity and participation in the lesson.

It is thought that the learning process will be supported through instructed music listening activities, it will contribute to the learning level of the student, and the effectiveness and permanence of learning. In this context, it is deemed necessary to include instructed music listening activities, especially in secondary school music lessons, which is the first step of music education with the music teacher.

However, for an effective teaching process supported by instructed music listening activities, the student must learn to be an active listener. This is made possible by the teacher's correct guidance on how to listen to music. For this reason, it is considered necessary that candidates of music teachers should be trained as qualified music listeners with the equipment they can direct their students in their professional life. It has been determined that there are different studies about music teacher candidates should be equipped with music listening activities in the literature.

In his research, Teleki (2013) concluded that there should be a lesson for music teacher candidates to be qualified music listeners. In the study carried out by Özkeleş and Nayir (2018), it is stated that listening to music within the scope of Music Forms course includes all the elements of musical communication, and that hearing and listening to music in professional music education are very different actions.

Based on these studies, it is important that music teachers have knowledge about planning and implementing these activities and that they have acquired the competence of using these activities in the process. With this in mind, providing in-service training programs for music teachers to use these activities will contribute to the realization of effective instructed music listening activities. Also, it is recommended to organize content for music teacher candidates to be equipped with teaching strategies for planning and implementing these activities in their undergraduate education and curriculum.

Considering the contribution of music activities supported with visual and auditory materials to the learning process, it is thought that the continuity of the instructed music listening activities in music lessons in the process will contribute to student achievement level and permanence of learning. With this in mind, it is recommended to give more places to the instructed music listening activities in the listening-singing learning area in music education programs.

\section{References}

Anderson, T. W. (2015). Mindful music listening instruction increases listening sensitivity and enjoyment. National Association for Music Education, 1-8. https://doi.org/10.1177/8755123314567905

Arslan, Ö. (2008). The effect of visual and auditory material use on students' academic success and level of retention in 8th grade Turkish Republic revolution history and Kemalism lesson in elementary education (Unpublished master's thesis). Dokuz Eylul University.

Aslan Efe, H., \& Bakır, N. (2019). The effects of discovery learning supported with learning boxes on student achievement and retention in science. Adlyaman Üniversitesi Eğitim Bilimleri Dergisi, 9(2), 250-270. https://doi.org/10.17984/adyuebd.533479

Aytan, T., Güneş, G., \& Uysal, G. (2018). The effect of listening texts in 6th grade turkish coursebook on students' vocabulary. Uluslararası Ders Kitapları ve Eğitim Materyalleri Dergisi, 1(1), 1-11. Retrieved from https://dergipark.org.tr/en/download/article-file/587792

Baldridge, W. R. (1984). A Systematic investigation of listening activities in the elementary general music classroom. Journal of Research in Music Education, 32(2), 79-93. https://doi.org/10.2307/3344975

Campbell, S. P. (2005). Deep listening to the musical world. Music Educators Journal, 92(1), 30-36. https://doi.org/10.2307/3400224

Çelik, B. (2010). Use of videotapes in piano education. Gazi Eğitim Fakültesi Dergisi, 30(3), 785-800. Retrieved from http://www.gefad.gazi.edu.tr/tr/download/article-file/77013

Cusano, M. J. (2004). Music specialists'beliefs and practices in teaching music listening. ProQuest Dissertations and Theses, Indiana University, ABD. Retrieved from 
https://search.proquest.com/docview/304986754?pq-origsite=gscholar\&fromopenview=true

Erden, O. (2012). Effect of teaching visual computer-aided learning materials. Ticaret ve Turizm Eğitim Fakültesi Dergisi, 2, 102-111.

Georgii-Hemming, E., \& Kvarnhall, V. (2015). Music listening and matters of equality in music education. Swedish Journal of Music Research, 2, 27-44. Retrieved from https://musikforskning.se/stm-sjm/sites/default/files/pdf/Georgii-Hemming_Kvarnhall\%20STM\%E2\%80\% 93SJM\%202015.webb_.pdf

Gülen, S., \& Demirkuş, N. (2014). The effects of visual material on students'achievement in "the solar system and beyond: mystery of space" unit. Yüzüncü Yll Üniversitesi Eğitim Fakültesi Dergisi, XI, 1-20. Retrieved from https://dergipark.org.tr/tr/download/article-file/146224

Güzel, B. B., Çakır, H., \& Çelen, Y. (2020). Student opinions on video supported violin teaching via youtube. Bilim, Eğitim, Sanat ve Teknoloji Dergisi (BEST Dergi), 4(1), 31-43. Retrieved from https://www.bestdergi.net/index.php/bestdergi/article/view/37/pdf

Hargreaves, J. D., \& Colman, A. M. (1981). The dimensions of aesthetic reactions to music. Psychology of Music, 9(1), 15-20. https://doi.org/10.1177/03057356810090010301

Kaptan, S. (1995). Scientific research and statistical technique. Tekışıkweb Ofset.

Karasar, N. (2008). Scientific research method. Nobel Yayınevi.

Kratus, J. (2017). Music listening is creative. Music educators journal, 103(3), 46-51. https://doi.org/10.1177/0027432116686843

Mamlok, D. (2017). Active listening, music education, and society. In Oxford Research Encyclopedia of Education, Oxford University Press. https://doi.org/10.1093/acrefore/9780190264093.013.186

Martinez, C. L. (2015). Active listening as the core method in teaching the elements of music. Alipato: A Journal of Basic Education, 6, 9-30. Retrieved from https://journals.upd.edu.ph/index.php/ali/issue/view/482

Ministry of National Education. (2018). Music lesson curriculum. Retrieved from http://mufredat.meb.gov.tr/Dosyalar/2018129173048695-1-8\%20M\%C3\%BCzik\%20\%C3\%96\%C4\%9Freti m\%20Program\%C4\%B1\%2020180123.pdf

Mobbs, A., \& Cuyul, M. (2018). Listen to the music: Using songs in listening and speaking classes. English Teaching Forums, 22-29.

Özen, C. (2016). The differences between music listening habits of teacher candidates (Unpublished master's thesis). Gazi University.

Özkeleş, S., \& Nayir, E. A. (2018, November-December). Methods of development of knowledge and skills related to listening within music forms course, 2. International symposium on innovative approaches in scientific studies, Samsun.

Reitan, I. E. (2013). Listening to music - with professional ears (A study of orchestral musicians' ways of listening). Aural perspectives, On musical learning and practice in higher music education, NHM Publikasjoner. Retrieved from https://nmh.brage.unit.no/nmh-xmlui/handle/11250/274226

Şenoğlu Özdemir, C., \& Can, A. A. (2019). Listening in music, types of listening and music teaching students' listening approaches. Illkögretim Online, 18(1), 367-388. https://doi.org/10.17051/ilkonline.2019.527631

Sims, W. L., \& Nolker, D. B. (2002). Individual differences in music listening responses of kindergarten children. Journal of Research in Music Education, 50(4), 292-300. https://doi.org/10.2307/3345356

Tekeli, B. (2013). Curriculum design proposal for listening to music and culture course from music teachers candidate point of views (Unpublished master's thesis). Gazi University.

Todd, J. R., \& Mishra, J. (2013). Making listening instruction meaningful: A literature review. Update: Applications of Research in Music Education, 31(2), 4-10. https://doi.org/10.1177/8755123312473609

Woody, R. H. (2004). Reality-based music listening in the classroom: Considering students' natural responses to music. General Music Today, 17(2), 32-39. https://doi.org/10.1177/10483713040170020106 


\section{Copyrights}

Copyright for this article is retained by the author(s), with first publication rights granted to the journal.

This is an open-access article distributed under the terms and conditions of the Creative Commons Attribution license (http://creativecommons.org/licenses/by/4.0/). 